Ocean Engineering

March 2015, Volume 97 Pages 74-81

http://dx.doi.org/10.1016/j.oceaneng.2015.01.003

http://archimer.ifremer.fr/doc/00251/36215/

(c) 2015 Elsevier Ltd. All rights reserved.

\title{
An empirical model to predict the lifetime of braided HMPE handling ropes under cyclic bend over sheave (CBOS) loading
}

\author{
Davies Peter ${ }^{1,{ }^{*}}$, Francois M. ${ }^{2}$, Lacotte Nicolas ${ }^{1}$, Vu Thanh Do ${ }^{1,3}$, Durville Damien ${ }^{3}$
}

${ }^{1}$ Ifremer, Centre de Bretagne, Marine Structures Laboratory, 29280 Plouzané, France

${ }^{2}$ Bureau Veritas,Marine and Offshore Division, 92200 Neuilly-Sur-Seine, France

${ }^{3}$ Ecole Centrale de Paris, MSSMat Laboratory, 92290 Chatenay-Malabry, France

* Corresponding author : Peter Davies, Tel.: +33 298224777 ; email address : peter.davies@ifremer.fr

\begin{abstract}
:
Repeated bending over sheaves is one of the main causes of failure of synthetic fibre ropes used in marine operations. There are few published results available and even fewer models allowing lifetime to be estimated. A large new set of data from cyclic bend over sheave (CBOS) tests on $250 \mathrm{kN}$ break load braided HMPE synthetic ropes is presented first, both tests to failure and interrupted tests followed by residual strength measurements. These data are analysed in order to propose an empirical lifetime model. This is identified using constant load tests, then evaluated for variable load sequences. A methodology to include rope lifetime prediction in handling system design is then discussed.
\end{abstract}

\section{Highlights}

A large new set of data from cyclic bend over sheave (CBOS) tests. An analysis of these data in terms of lifetime. Validation of the analysis using additional 2-load and variable load tests.

Discussion of the consequences for safety of ocean handling systems.

Keywords : Fibre rope, Bending, Sheave, Abrasion, Fatigue 


\section{Introduction}

Synthetic fibre ropes offer many advantages for deep water handling operations, mainly due to their light weight in water compared to steel. Ropes made from high performance fibres such as aramids and HMPE (high modulus polyethylene) also show excellent mechanical properties. These materials have been used for oceanographic applications such as deep sea coring for over 20 years, in the form of braids of diameters up to $40 \mathrm{~mm}$ and break loads up to $1000 \mathrm{kN}$ (Davies et al, 2013). For these applications the payload is a long tube below a large weight, so loss due to rope failure is inconvenient but not critical. However, new large synthetic fibre ropes are now being considered for offshore operations and in particular the installation of subsea equipment at depths of 3000 meters or more. Here the payload may weigh 250 tons and consist of very expensive components for automated well management. Under these conditions it is essential to know how the lifting system safety coefficient evolves with time and the remaining load capacity. This is the ultimate objective of the present work. There has been some work on steel wire ropes for offshore handling, e.g. (Feyrer 2007, Nabijou \& Hobbs 1995, Vennemann et al 2008), but synthetic fibre ropes are less well-known. There have been some industry studies, the DISH (Deep water Installation of Subsea Hardware) Joint Industry Project (2001-2006) involved some testing, and various other offshore projects using synthetic ropes are underway (Tornqvist et al 2011, Torben et al 2007, Gilmore et al 2008, Thomas \& Gilmore 2009), but few results have been published to date. The ropes of interest for these applications, both oceanographic and offshore, are braided. These are torque-balanced and easy to splice. Various authors have discussed the mechanics of braided ropes (Wu et al 1995, McKenna et al 2004), which may involve 8,12 or 24 strands. One particularity of these ropes is the large number of internal crossover points between strands which may be the source of internal abrasion. Leech (2002) has described various modes of relative motion in different rope structures. He underlines the complexity of these materials, six modes of relative movement are identified with scissoring of particular importance in braided and plaited ropes. This is one of very few papers which describe the mechanisms which can lead to damage in fibre ropes. Modelling of fibre rope behaviour, even under simple tension loading, is very complex. Some results from twisted rope models were presented by Leech et al (2002) and Ghoreishi et al (2007), and there have been some attempts to model braided fibre structures e.g. (Picket et al, 2009), but there is currently no model capable of simulating the repeated loading of a braided rope over a sheave. Within the present project numerical modelling was performed, by applying software specifically developed for fibrous materials (Durville 2010 and 2011) and some first results have been presented (Davies et al 2013). However, that work will be presented in detail elsewhere. 
The present paper will first present experimental results from cyclic bend over sheave tests, then describe their analysis which has enabled an empirical lifetime model to be proposed. Results from this model will then be compared to results from some additional, more complex loading cases. Finally the proposed model will be discussed in terms of design of a deep sea handling line.

\section{Materials and Test methods}

The material tested throughout was a 12-strand braided rope of DSM SK75 grade HMPE fibres. The ropes were nominally of $19 \mathrm{~mm}$ diameter and were manufactured by Samson Ropes under the trade name AmSteel Blue ${ }^{T M}$. It should be emphasized that this is a standard rope design. There are several enhanced bending designs available commercially, some of which were also tested in the project (see Davies et al., 2013), and the approach developed here can be applied to other designs. The specimens tested were around 8 meters long, with eye splices at both ends. These were placed over $100 \mathrm{~mm}$ diameter loading pins. No end splice failures were observed during CBOS testing.

Initially tensile tests to failure were performed on a $1000 \mathrm{kN}$ capacity 10 meter long test frame, Figure 1a. This allowed the nominal rope break load of $250 \mathrm{kN}$ to be checked. Cyclic Bend over Sheave (CBOS) tests were then performed on a specially designed test frame, Figure $1 \mathrm{~b}$.

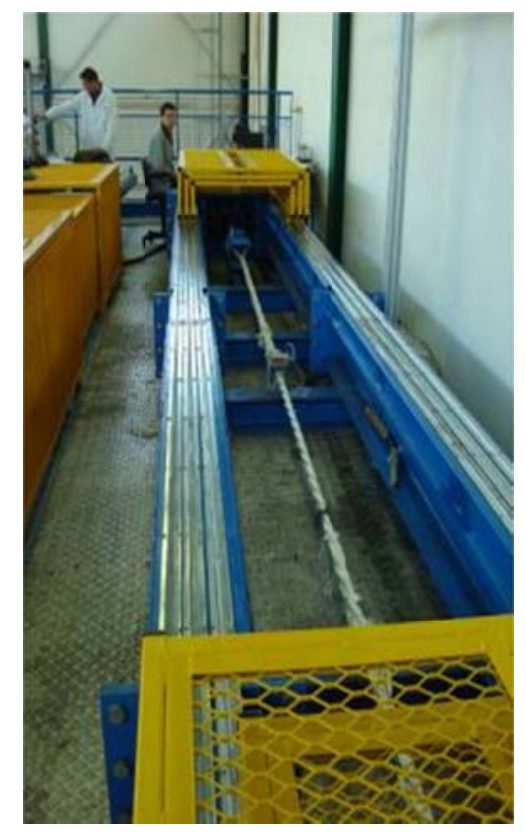

(a)

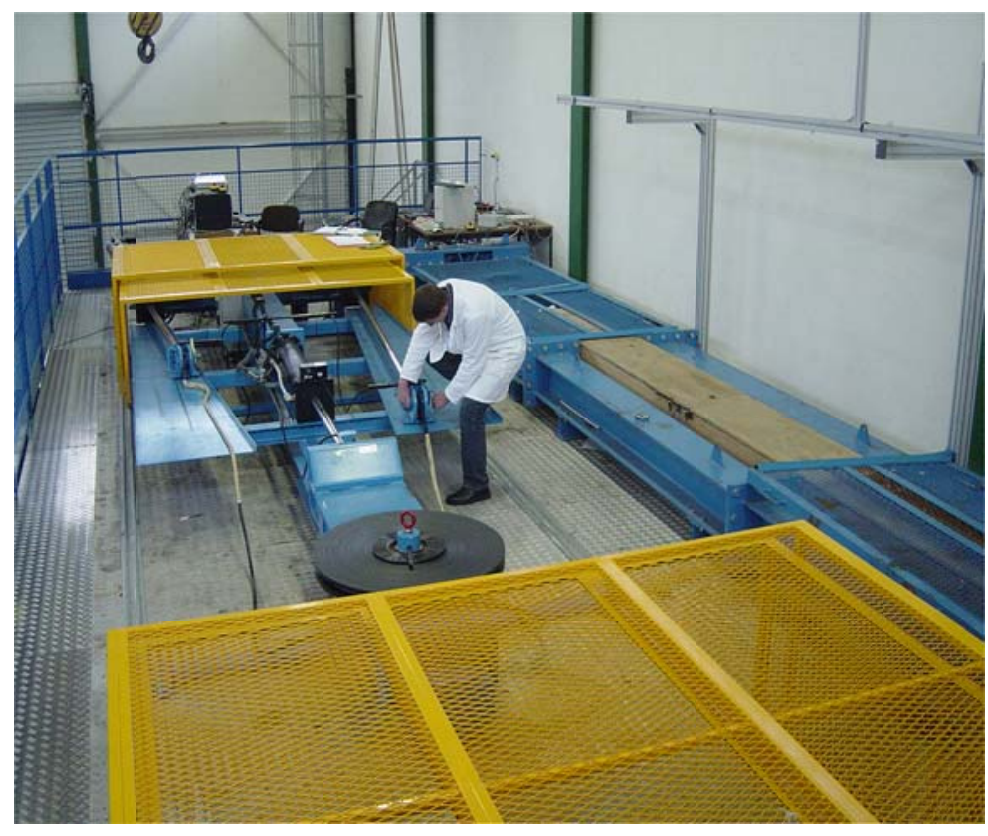

(b)

Figure 1. Test equipment;

a) $1000 \mathrm{kN}$ tensile test frame, b) Cyclic bend over sheave (CBOS) test frame.

The latter allows a rope to be put under constant tension by a central hydraulic piston, then the back-and-forth motion over the sheave is applied by two external pistons. The displacement applied 
was between \pm 350 and $\pm 400 \mathrm{~mm}$ for all tests, the pistons performed a complete loading cycle (two bending operations) in 20 seconds, For each test the load and displacement measurements of each piston (6 signals) were recorded continuously, at a frequency of $1 \mathrm{~Hz}$. An example is shown in Figure 2.

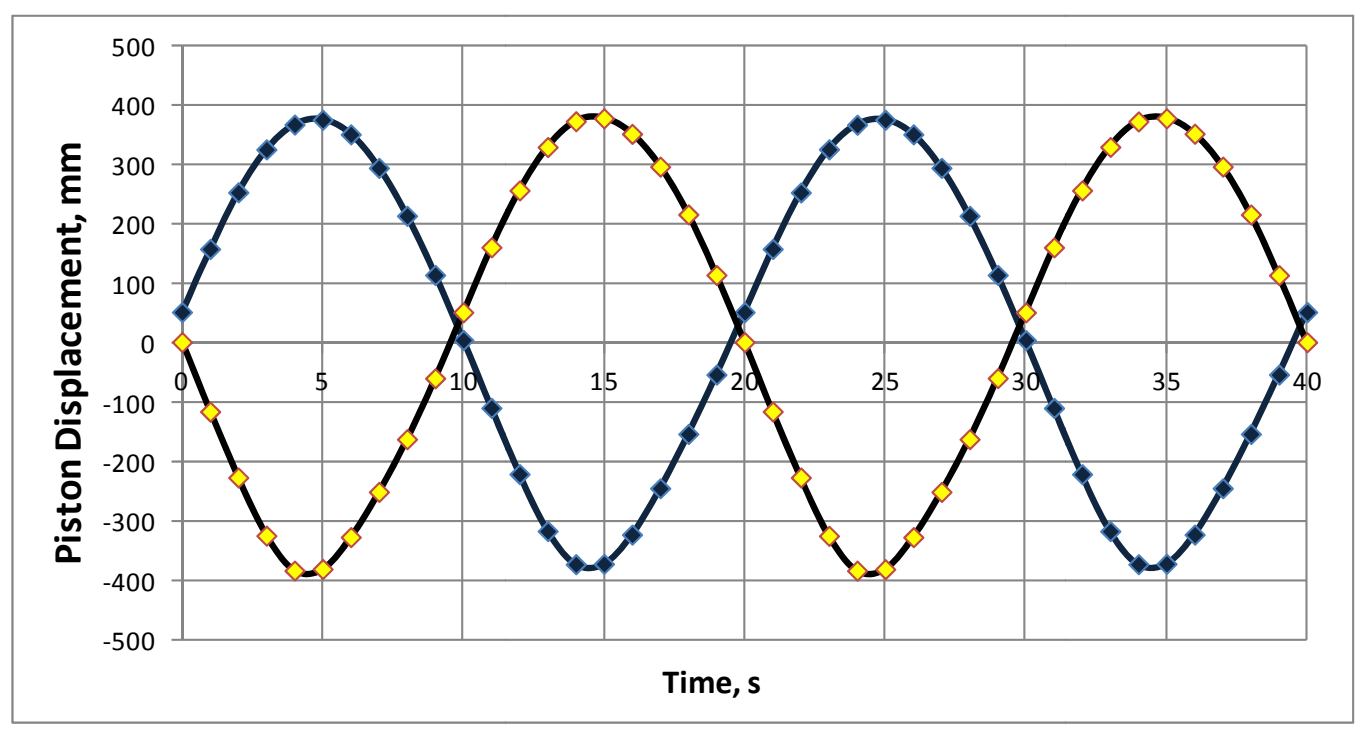

Figure 2. Example of two piston displacements during a test at a constant load of $40 \mathrm{kN}$.

Samples were continuously wetted with tap water for all tests at the entry and exit of the sheave, Figure 3.

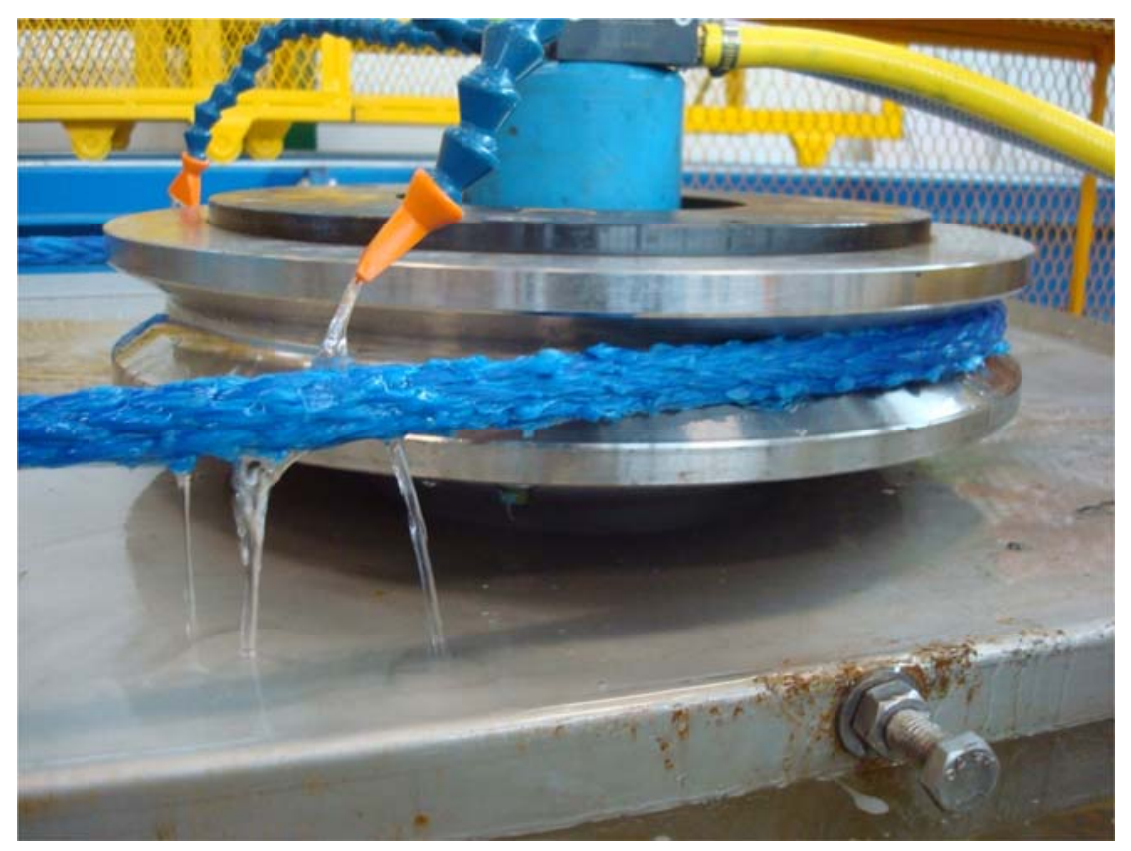

Figure 3. Wetting of sample on sheave during cycling 
At the start of the test each sample was manually subjected once to its maximum load level, before starting cycling, in order to bed in the rope. This avoided large initial displacements which make machine control more difficult. The servo-hydraulic load control programme was then started and the machine regulated first the applied load then adding the cyclic displacements. The test frame is controlled by three Zwick servo-hydraulic controllers, one for each piston, linked to a PC which allows the test conditions to be programmed using MecTest ${ }^{\mathrm{TM}}$ software.

In this study the sheave, made of stainless steel, had a (mean) diameter $\mathrm{D}$ of $380 \mathrm{~mm}$, to provide a $\mathrm{D} / \mathrm{d}$ ratio of 20 with respect to rope diameter $\mathrm{d}$, Figure 3.

\section{Results}

\section{Applied load-cycles to failure}

Figure 4 shows an applied load versus log(cycles to failure) plot for this material. Sixteen ropes have been tested, including 6 repeat tests at $40 \mathrm{kN}$ to examine variability. The coefficient of variation at that load level was $13 \%$. There is a progressive drop in lifetime as applied load increases. This evolution will be discussed in more detail below.

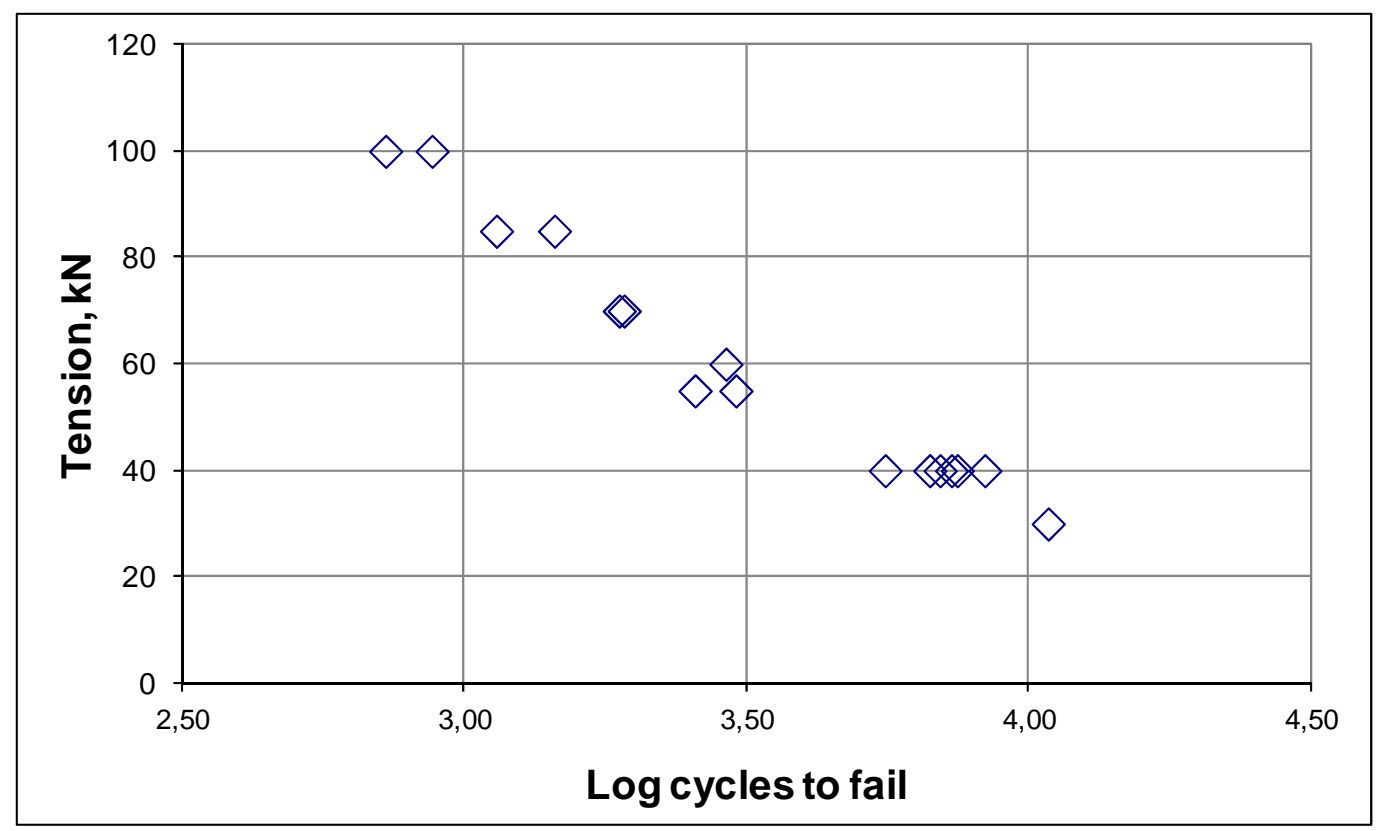

Figure 4. Applied tension versus log (cycles to failure)

Failure invariably occurs at the mid-length of the sample, in the region which has been subjected to two flexure loads per cycle. 


\section{Residual strength after cycling}

In order to examine how damage affects residual strength it is interesting to stop tests and to perform residual strength measurements. The question of how to measure residual strength then arises, either in straight tension or in bending on the sheave. These do not give the same result for a new rope, and preliminary tests showed that the latter result in lower break loads, both for new ropes and after cyclic loading, Figure 5 (Davies et al 2013). A direct tension value of residual strength (although a practical in-service retirement criteria) may therefore provide an over-optimistic evaluation of remaining properties in a deep sea handling application.

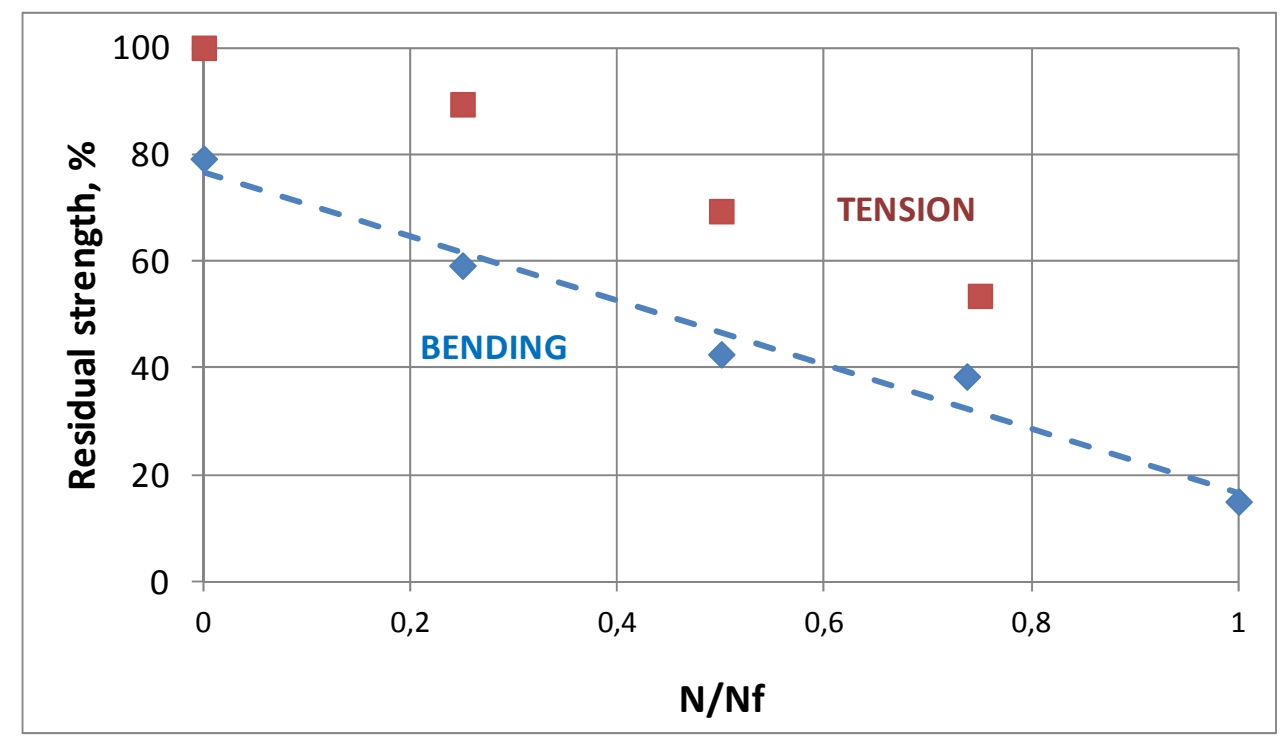

Figure 5. Comparison between residual strengths measured in direct tension

and by cyclic bending on the sheave at increasing load. Values normalized with respect to tensile break load.

This method of measuring residual strength by progressively increasing load while continuing to cycle on the sheave until failure was therefore retained. Based on the mean value of $\mathrm{N}_{\mathrm{f}}$ recorded in the T$\mathrm{N}_{\mathrm{f}}$ tests (Figure 4] a series of 24 tests at three different load levels were interrupted and residual strengths were measured in flexure on the sheave. Figure 6 shows residual strengths after cycling to different load levels. 


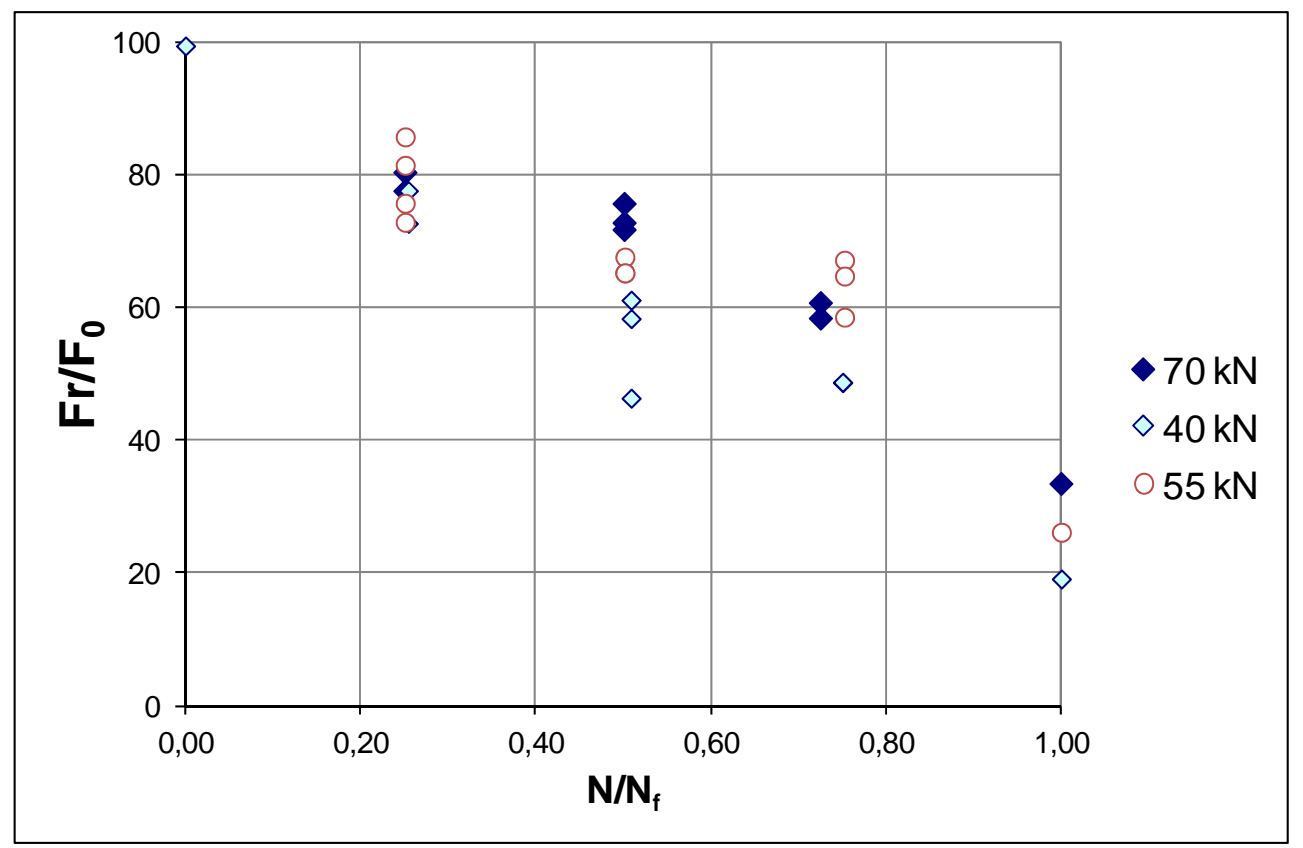

Figure 6. Residual strength in bending versus proportion of mean lifetime, for three applied load levels.

It is apparent that residual strength drops continuously with cycles for each load level.

Observations of damage reveal four distinct mechanisms. The first is a flattening of the rope surface in contact with the sheave, Figure $7 \mathrm{~b}$, as the rope conforms to the groove profile, producing a shiny continuous surface. This may involve local melting of the fibres. The second mechanism, presumably related to the high pressure exerted by the sheave, is an extrusion of fibre loops at the outer surface, Figure 7c. While these fibres may not be broken, and if the rope is then subsequently loaded in uniform tension they may be pulled back into the construction, they no longer carry load in flexure. This may partly explain the difference in residual strength between tension and flexure. The third mechanism is abrasion within the rope, mainly inter-strand, Figure $7 \mathrm{~d}$. The final mechanism is fibre breakage. These four mechanisms are not independent but act together, making failure analysis complex. The large release of energy at final failure can also result in fibre melting. It should be emphasized however, that at the applied CBOS load levels here (up to $50 \%$ of nominal break load) no damage was noted outside the section of the rope which passed over the sheave. 


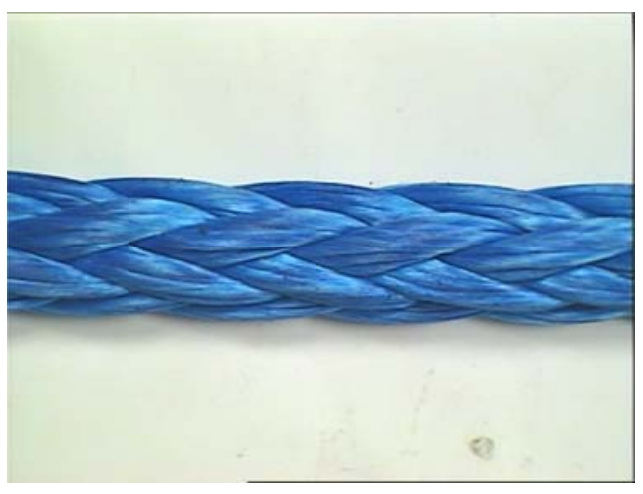

(a)

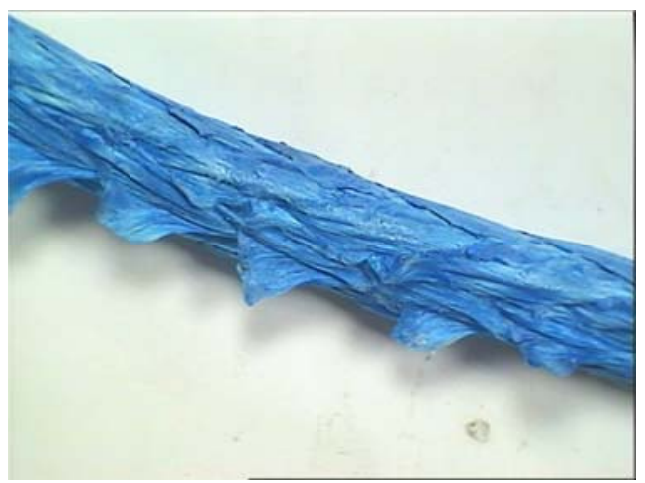

(c)

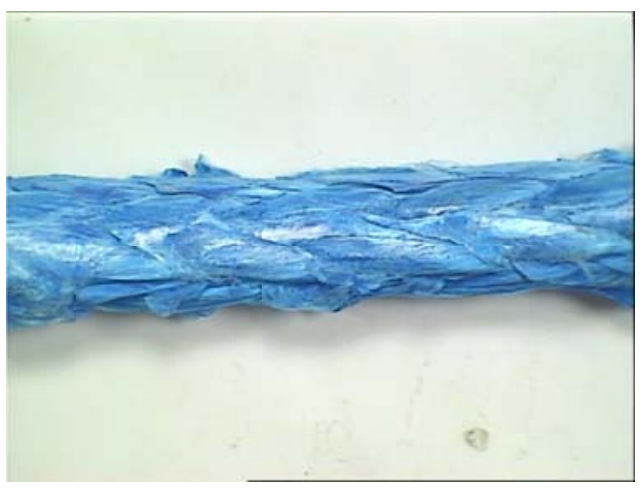

(b)

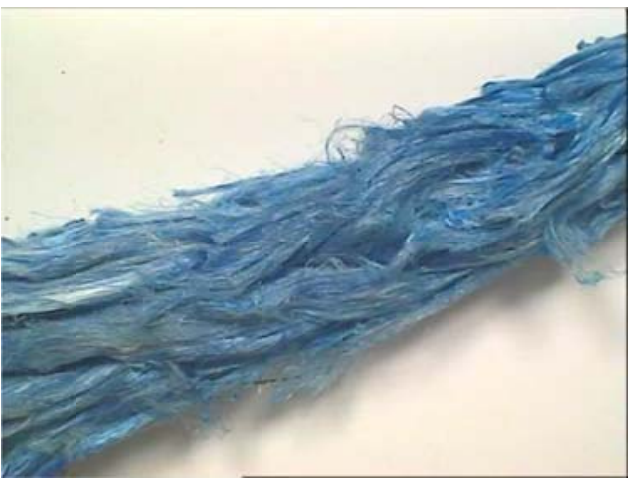

(d)

Figure 7. Damage mechanisms.

a) New rope, b) Inner surface, c) External extruded loops, d) Inter-strand abrasion

Numerical modelling has also indicated that the main energy dissipation is the result of internal abrasion, both between strands and between assembled yarns within the strands, and provided a tool which can be used to evaluate rope and sheave parameters to optimise lifetime (Davies et al 2013).

\section{Data analysis and Empirical model}

Based on these data the aim is now to establish an expression which will allow lifetime to be predicted under any cyclic loading conditions.

\section{Endurance}

First, trend lines are obtained by linear regression (least square fit) of $\log N_{f}$ (the number $N_{f}$ of machine cycles at failure - the number of CBOS cycles is twice that) versus T or logT (so with inverted axes, compared to figures 4 and 8 , that follow the usual presentation of T-N plots). 
The semi-log relation, commonly used for ropes, was initially considered but, although there is little difference between the two options over the range of tensions tested, the log-log relation (also a classical relation in fatigue/endurance plots) is preferred here, for the following reasons:

- it leads to a better fit than the semi-log relation, for the range of tension tested, with a lower coefficient of variation (by about $25 \%$ ) and a more uniformly distributed scatter,

- the trend towards lower tensions - although hypothetical - does not present the same unrealistic end as the semi-log relation that gives a finite endurance at a zero load (further tests would be indeed required to confirm this).

For this rope, the (mean) endurance is thus given by:

$$
\log N_{f}=7.42-2.25 * \log T \quad(\text { Equation 1) }
$$

The scatter of data around this relationship shows a coefficient of variation of $13 \%$, about the same as the scatter observed by repeat tests (see above). Figure 8 below shows the above relation and, for illustration, the scatter band limits corresponding to probabilities of failure of $2.5 \%$ and $97.5 \%$ ( 2.12 standard deviations (Bureau Veritas 1994)).

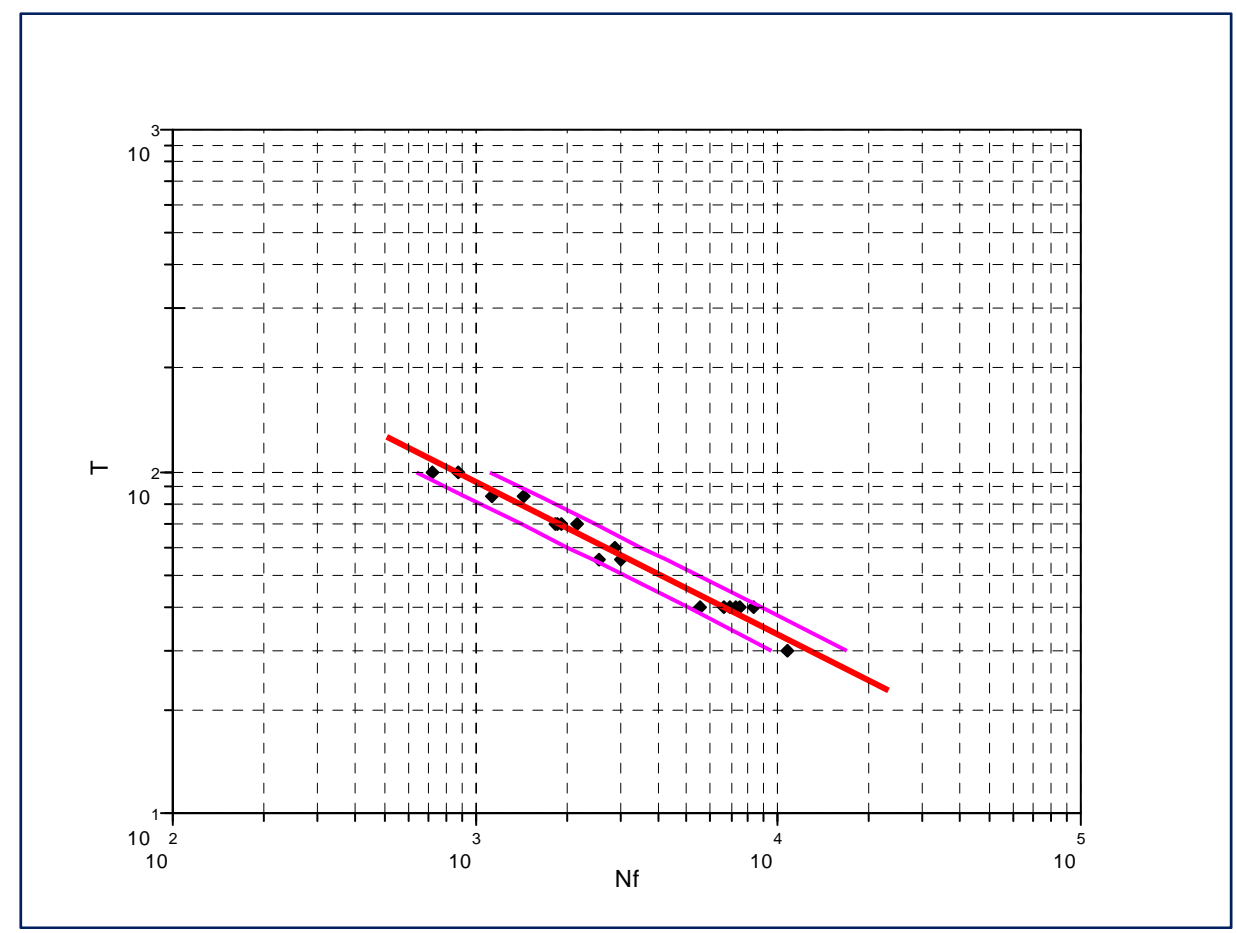

Figure 8. CBOS endurance: T versus $N f$. 


\section{Residual Strength on sheave}

Test results presented above (Figure 6) show that the in-situ residual strength of a rope - the residual strength "while cycling" Rs $s_{w c}$ - is decreasing with the number of cycles, indicating a progressive degradation mechanism of the rope. The initial $R s_{w c}, R_{1}$, after one cycle (in fact around 50 cycles are needed in order to increase the load to failure progressively) was measured to be $209 \mathrm{kN}$ (average from three tests, with very small scatter); this is lower by around $20 \%$ than the mean straight pull break load of a new rope, $260 \mathrm{kN}$. Besides, after $\mathrm{N}_{\mathrm{f}}$ cycles, the rope fails under the applied tension $\mathrm{T}$, thus the "final" Rs $s_{W c}$, at $N_{f}$ cycles, is equal to $T$.

The strength decay under cycling at a given tension is approximately proportional to the applied number of cycles and, as a first approximation, a decay from $R_{1}$ to $T$ as a linear function of $N / N_{f}$ (using the value of $\mathrm{N}_{\mathrm{f}}$ predicted by Eq 1) was considered, as illustrated in figure 9 below. This model has the advantage that it does not rely on any additional parameters (but only on those of the T- $\mathrm{N}_{\mathrm{f}}$ curve and the value of $R_{1}$ ), but it is not accurate: Rs is over-predicted at small $N / N_{f}$ (around 0.25 ), and underpredicted for $\mathrm{N} / \mathrm{N}_{\mathrm{f}}$ above 0.5 .

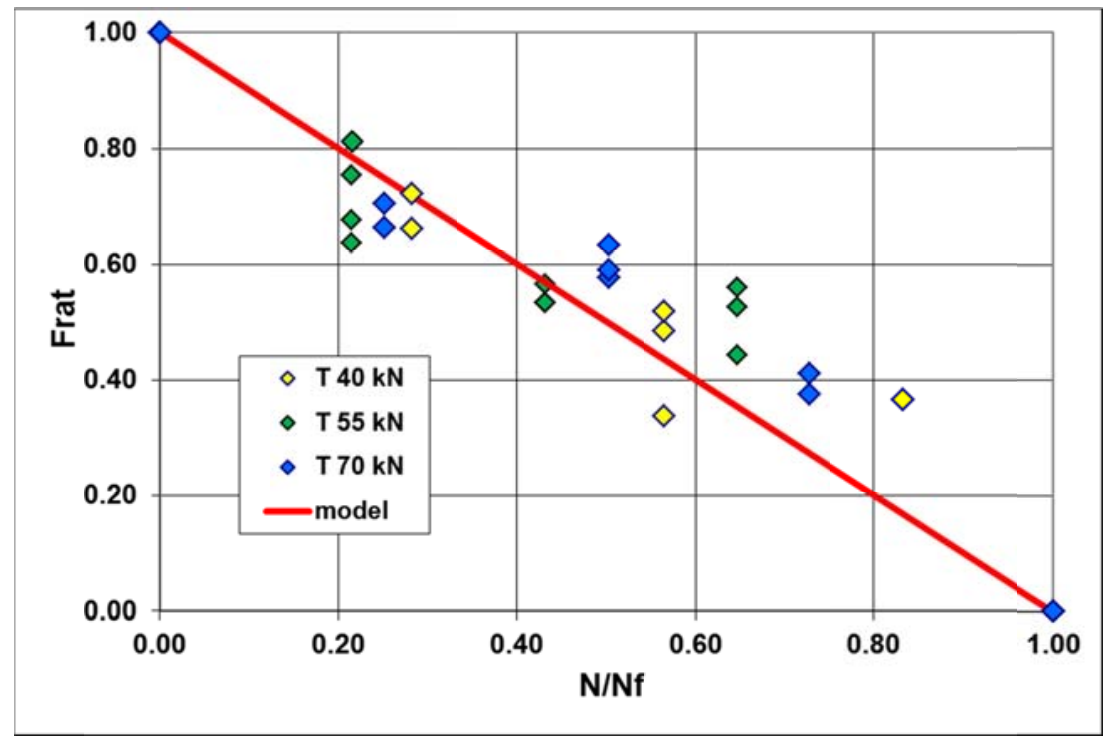

Figure 9. Linear model of strength degradation : Frat $=(R s-T) /(R 1-T)$ versus $N / N_{f}$

Indeed, as apparent - in spite of scatter - in figure 9, Rs versus $\mathrm{N}$ (or $\mathrm{N} / \mathrm{N}_{\mathrm{f}}$ ) shows an $\mathrm{S}$ shape, with a drop of residual strength from $R_{1}$ - of the order of $20 \%$ - at the beginning of cycling (at $N / N_{f}$ before say 0.2 ), then a progressive degradation of Rs with $\mathrm{N}\left(\right.$ or $\mathrm{N} / \mathrm{N}_{\mathrm{f}}$ ), at an almost constant rate for a given tension $\mathrm{T}$, finally a drop to $\mathrm{T}$, that seems more abrupt at higher $\mathrm{T}$. However, attempts to model the whole curves with a reasonable number of parameters were unsuccessful. 


\section{Residual strength model}

Comparatively, i.e. when plotted versus $\mathrm{N} / \mathrm{N}_{\mathrm{f}}$, the rate of strength loss in the middle part appears lower for higher $\mathrm{T}$. Indeed, the rate of strength loss $\mathrm{dRs} / \mathrm{dN}$ is found to be about proportional to $\mathrm{T}^{\mathrm{b}}$, with $b$ around 1.5, i.e. with a different trend than the $T-N_{f}$ curve (where $m=2.25$ ). As this middle part is the most relevant to assess the safety of rope in service, a model of it is proposed, based on the above. This can be written as :

$$
R_{S}(N, T)=R_{2}-Q * N \quad \text { (Equation 2) }
$$

with :

- $Q$ the rate of strength loss, $Q=a_{r} T^{b r}$,

- $\mathrm{R}_{2}$ the value at the origin, as if the initial drop occurred during the first cycle(s).

The parameters of the model $\left(R_{2}, a_{r}, b_{r}\right)$ are obtained by a (non linear) least square fit, using Scilab (C INRIA ENCP) software. This fit is made on $\log (\mathrm{Rs})$, so that the calculated error is a relative error (see Figure 10 below). Besides, as after the $\mathrm{N}$ cycles at $\mathrm{T}$, some additional cycles at an increasing tension are run to get Rs, inducing some additional degradation, a (small) correction to Rs is made (see Figure 11), based on the model (thus extrapolating $Q$ to a somewhat higher $T$ ). This is taken into account in the least square fit.

With the available data (24 data points for 3 tensions), the following results are obtained, with a COV close to $8 \%$ :

$$
R_{2}=183 \mathrm{kN}, \quad a_{r}=0.6410^{-4}, \quad b_{r}=1.49
$$

The statistical distribution of model error is found close to a normal distribution, with the exception of a single outlier: the low point of Rs at $\mathrm{N}=3750$, for $\mathrm{T}=40 \mathrm{kN}$.

\section{Design value of Residual Strength}

As for classical breaking strength assessment, a design (characteristic) value Rd of the RsWC may be taken as the mean Rs (from the model presented above) minus $\mathrm{k}$ standard deviations.

For illustration, $\mathrm{k}=1.5$ is taken after Madsen et al (1986), so as to give about the same confidence level as the classical "mean minus 2 standard deviations of five tests". $\mathrm{Rd}$ is thus given by:

$$
\operatorname{Rd}(\mathrm{N}, \mathrm{T})=162-0.5710^{-4} \mathrm{~T}^{1.5} * \mathrm{~N} \quad \text { (Equation 3) }
$$

Rs and Rd are shown on figure 10, together with data points. 


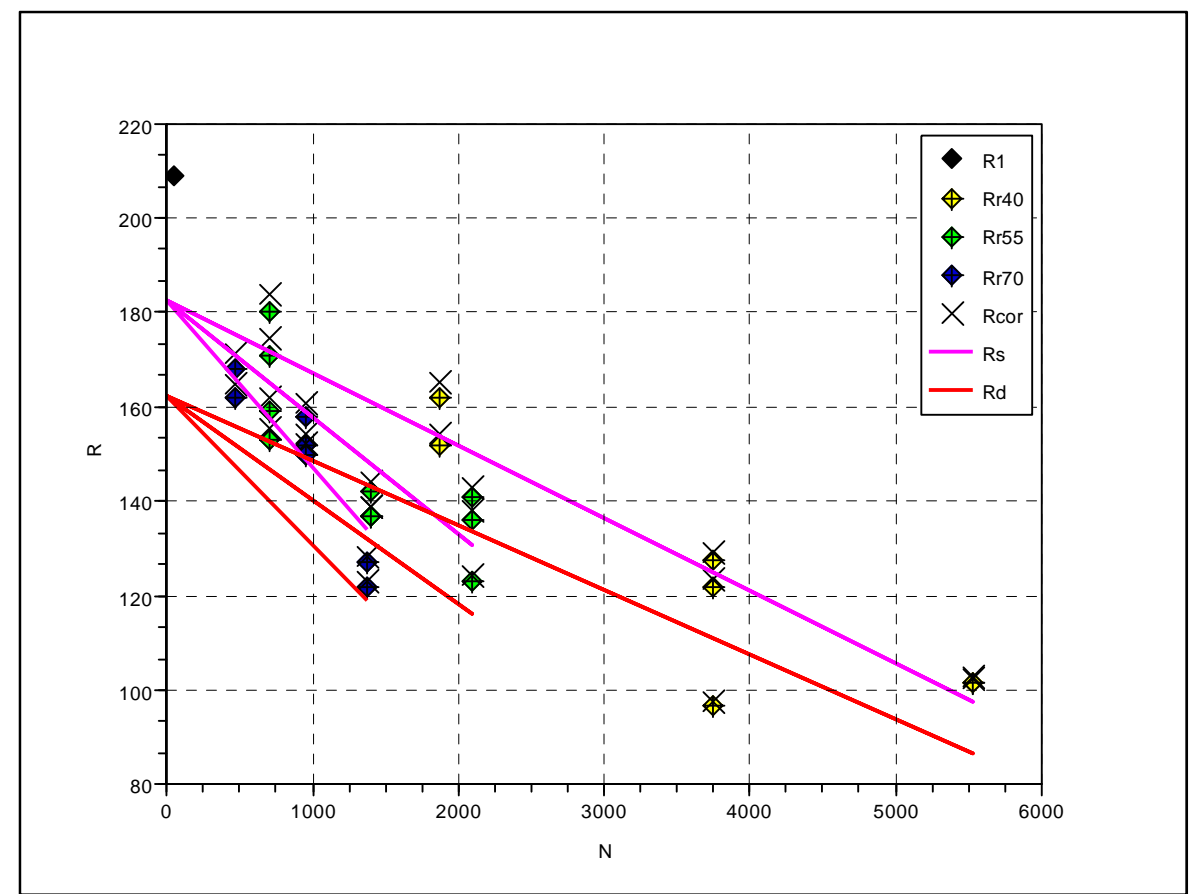

Figure 10. Residual Strength model : Rs $s_{w c}$ versus $N$ :

data for the 3 cycling tensions ( + : without correction, $x$ : with correction), model mean values $R s$ (pink line), and design values $R d$ (red line)

\section{Additional tests}

In order to be able to evaluate this approach, by applying it to test results which were not used to identify the model, two additional series of tests were performed; two-load and variable load tests, Figure 11. Results are shown in Table 1.

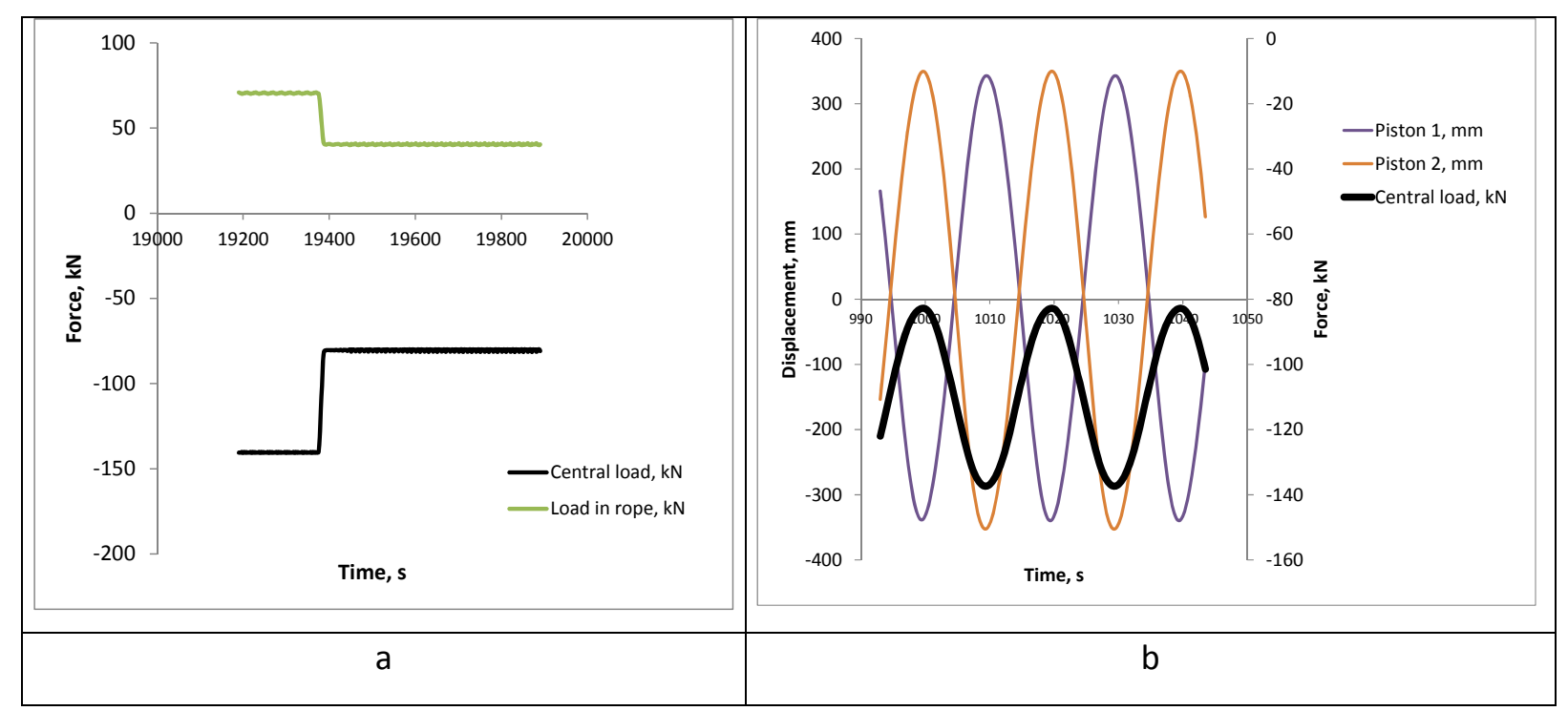

Figure 11. Additional tests performed to evaluate model,

a) 2-load, recording corresponds to load change from 70 to $40 \mathrm{kN}$,

b) variable load, showing in-phase displacements.

(NB Central load applied by piston on sheave in compression is $2 x$ the tensile load generated in rope) 


\begin{tabular}{|c|c|}
\hline Sequence & Cycles to failure, Nf \\
\hline$\approx 50 \% \mathrm{Nf}(3750)$ at 40 then $\mathrm{Nf}$ at $70 \mathrm{kN}$ & $372,225,532$ \\
\hline$\approx 50 \% \mathrm{Nf}(950)$ at 70 then $\mathrm{Nf}$ at $40 \mathrm{kN}$ & $5004,6783,4027$ \\
\hline Variable: $55 \pm 15 \mathrm{kN}$ In-phase & $4150,3773,3217$ \\
\hline Variable: $55 \pm 15 \mathrm{kN}$ Out-of-phase & $3312,3617,3238$ \\
\hline
\end{tabular}

Table 1. Results from additional CBOS tests performed to evaluate model

\section{Two-load tests}

In the "two-load test", a rope was cycled under tension $\mathrm{T}_{1}$ for $\mathrm{N}_{1}$ cycles (about $50 \%$ ) of the endurance $N_{f 1}$ at $T_{1}$ ), then under tension $T_{2}$ for $N_{2}$ cycles, until failure.

Following a classical Miner sum, $\mathrm{N}_{2}$ would be expected to be a fraction (also about $50 \%$ ) of the endurance $\mathrm{N}_{\mathrm{f} 2}$ at $\mathrm{T}_{2}$, satisfying the equation :

$$
\left(N_{1} / N_{f 1}\right)+\left(N_{2} / N_{f 1}\right)=1 \quad \text { (Equation 4) }
$$

So $\mathrm{N}_{2}$ would be expected to be also about $50 \%$ of the endurance $\mathrm{N}_{\mathrm{f} 2}$.

Results in Table 1 indicate that $\mathrm{N}_{2}$ does not correspond to this: it is much lower for $\mathrm{T}_{1}=40 \mathrm{kN}$, and much higher for $T_{1}=70 \mathrm{kN}$. This is in line with the observation - made previously - that a smaller tension is comparatively more damaging, and it can be interpreted with the proposed model of Rs:

From equation 2, the (mean) residual strength Rs after $\mathrm{N}_{1}$ cycles at $\mathrm{T}_{1}$ can be evaluated, then the number of cycles $\mathrm{N}_{1 \text { eq }}$ under $\mathrm{T}_{2}$ that would have resulted in the same Rs. The corresponding total number of cycles at failure under $T_{2}$ can be then evaluated as:

$$
\mathrm{N}_{2 \mathrm{t}}=\mathrm{N}_{1 \mathrm{eq}}+\mathrm{N}_{2} \quad \text { (Equation 5) }
$$

In figure 12 below, $\mathrm{N}_{2 t}$ is compared with the $\mathrm{N}_{\mathrm{f}}$ model: The results are well within the scatter band of $\mathrm{N}_{\mathrm{f}}$, thus providing a validation of the Residual Strength model. 


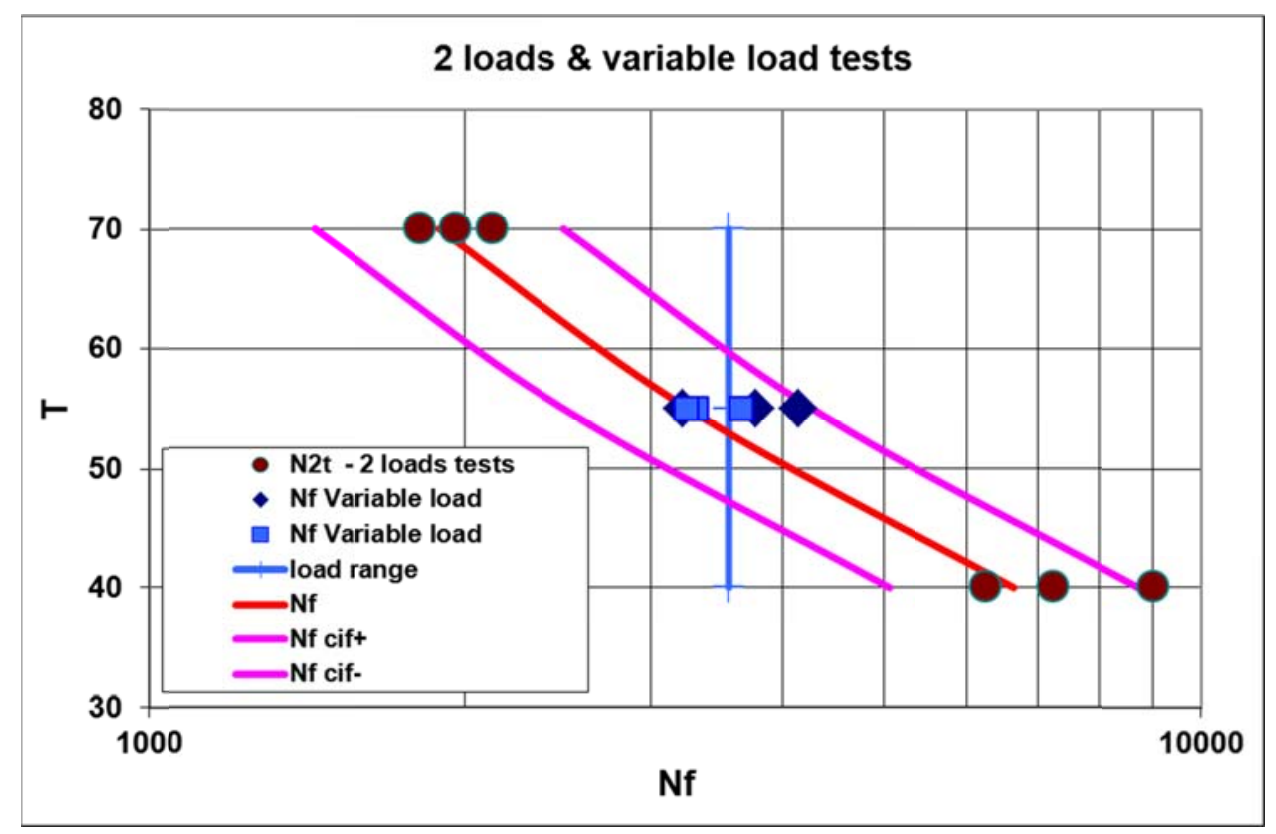

Figure 12. Rope endurance under variable tension

\section{Variable load tests}

Under real conditions, the tension is not constant during an operation, but fluctuating due to dynamic actions. In order to simulate such conditions two series of three tests were performed with a (harmonic) tension variation, between 40 and $70 \mathrm{kN}$ (see Figure 12b), at the same period as cycling on the sheave, and either in phase or in quadrature with this cycling (thus varying the instant of maximum tension with respect to rope position on sheave that, in a real system, may differ case by case). Results show a similar scatter to that of the $\mathrm{T}-\mathrm{N}_{\mathrm{f}}$ data, a limited effect of phase, and an endurance on the upper side of the range for endurance under mean tension. As failure necessarily occurs at the maximum tension, this indicates that the equivalent tension (in terms of rope degradation) is possibly (and quite surprisingly) lower, at least not higher than $\mathrm{T}_{\text {mean }}$. This validates the use of $T_{\text {mean }}$ to evaluate rope strength degradation, using the model presented above.

\section{Design approach}

\section{General considerations- subsea lowering system}

In a ship borne sub-sea lowering system, the line will be subject to CBOS. During lowering, the number of bend-unbend cycles in a given section of the rope will be equal to the number of passages over winch drum and sheaves. More intense CBOS might happen on some sections of the rope: 
- If up and down movements are performed, for any reason,

- Principally when the system is kept (near) stationary and/or with AHC (Active Heave Compensation) - e.g. in the near bottom phase of the operation, or accidentally - with one bend-unbend cycle per wave cycle (possibly two, in the case of large amplitude travel of the rope over the sheaves). Different systems/operating conditions might also lead to the same situation.

At the same time, line tension will be fluctuating, due to the effect of - principally - the wave induced vertical motion of the supporting vessel. The tension history can be evaluated e.g. by time domain simulation (the system of the suspended body and the line can be modelled by a simple single degree of freedom (mass and spring) model under an imposed displacement, but the moving body is subject to non-linear drag forces). The natural period of the system is a function of line length, and the maximum tension $T_{\max }$ typically occurs with resonance to wave induced excitation.

The maximum tension $T_{\text {dynmax }}$ can be related to the mean (static) tension $T_{\text {mean }}$ (the suspended (buoyant) weight of the body) writing : $\quad T_{\text {dynmax }}=\mathrm{DTF}^{*} \mathrm{~T}_{\text {mean }}$

Depending on the system and the conditions, the dynamic tension factor DTF may approach the value of 2 , and possibly exceed 2 if snap loads in the line are not avoided.

\section{$\underline{\text { Safety Factors - Endurance }}$}

The classical approach to size or verify a system is to check the Factor of Safety FoS, the ratio between the breaking strength of the new line BS, and the applied static tension Tmean. Indeed FoS is a global factor that accounts for both dynamic actions, degradation of rope strength on sheave with time, and a (true) Safety margin, all in an implicit way.

Some codes for lifting appliances (e.g. EN1385-2:2004 on offshore cranes) also specify a Safety factor between BS and Tmax, in which line degradation with time is also not explicitly accounted for.

With endurance data available, a classical method to assess system acceptable life time - e.g. in offshore moorings - is to use the T-Nf endurance data, a "Miner Sum" to combine the effect of different tensions, and a "damage factor" - typically in the range of 2 to 10 - to get a safety margin ( $\mathrm{Nf}$ being the number of cycles at failure, i.e. the point at which the rope is no longer able to withstand the suspended weight). But this assessment will not give any information on the actual safety of an operation with respect to the risk of failure of the rope. Besides, as noted from the results of 2-load tests, the effect of different tensions cannot be combined by a Miner sum. 
However, with the data of Rs $\mathrm{sc}_{\mathrm{wc}}$, an explicit relation can be built, between the (allowable) number of cycles $\mathrm{Na}$ and the actual Safety factor, i.e. the ratio between the in-situ rope strength at a given time, and the maximum line tension :

$$
S F_{d y n}=R s_{W c} / T_{d y n m a x} \quad(\text { Equation } 6)
$$

This is presented in the sections below.

\section{Life time for a given Safety factor}

From the above, the required residual strength at a given time may be written:

$$
\mathrm{Rs}_{\mathrm{WC}}=\mathrm{SF}_{\mathrm{dyn}} * \mathrm{~T}_{\text {dynmax }}=\left(\mathrm{SF}_{\mathrm{dyn}} * \mathrm{DTF}\right) * \mathrm{~T}_{\text {mean }}=\mathrm{TLF}^{*} \mathrm{~T}_{\text {mean }} \quad \text { (Equation 7) }
$$

In which TLF $=\mathrm{SF}_{\mathrm{dyn}}$ * DTF is a global factor, accounting for both dynamic actions and the expected Safety margin.

With the model of (design) Rswc, the allowable $\mathrm{N}$ until which a given TLF is satisfied can be derived, and is plotted in figure 13 below.

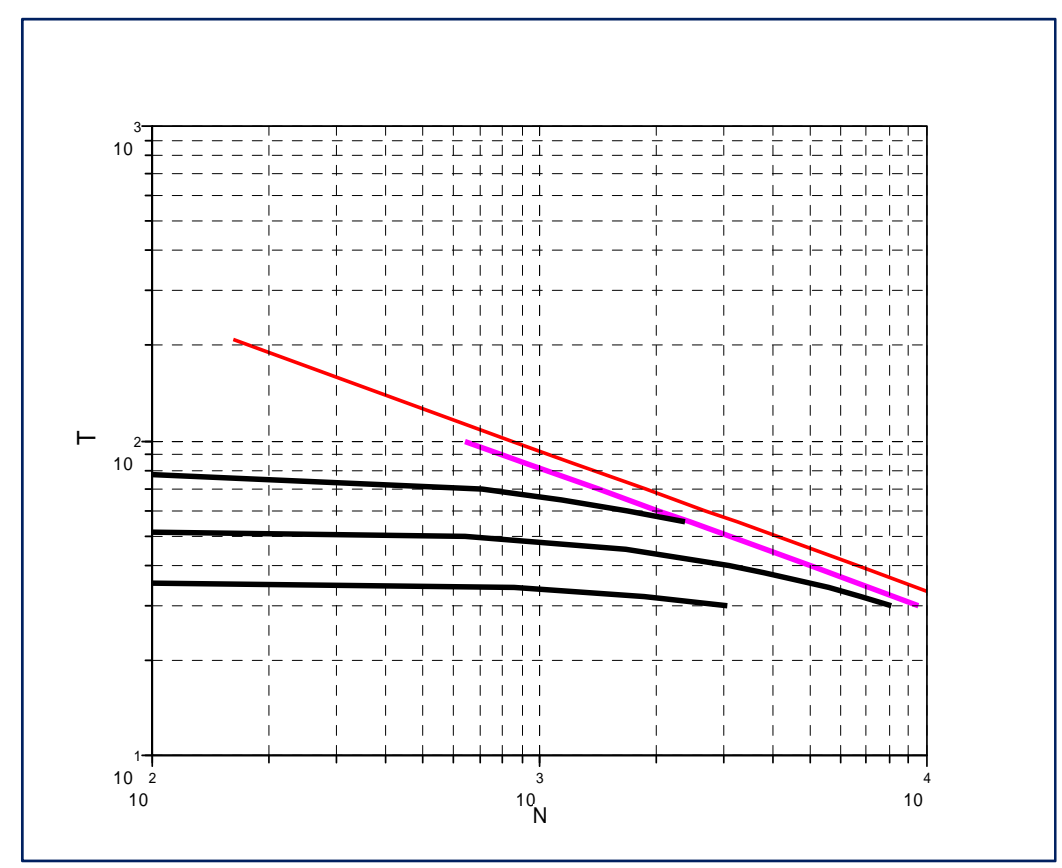

Figure 13. Tension versus allowable $N$ (bold black lines) for 3 values $(2,3$, and 4.5) of TLF, $T-N_{f}:$ mean (red line) and design (bold pink line) also shown for reference.

The curves appear quite flat, with an (average) slope lower than the slope of the $T-\mathrm{N}_{\mathrm{f}}$ curve, and some downward curvature (indeed, the whole curve, for a given tension is below $R_{2}$ / TLF, in which $R_{2}$ $(162 \mathrm{kN})$ is itself only $65 \%$ of the rope MBS). These curves clearly show that the practice of taking a 
fraction of $\mathrm{N}_{\mathrm{f}}$ for the allowable endurance, as mentioned above, would not lead to consistent safety levels.

This is however a very conservative approach, as it assumes that the rope is under the same nominal (mean) tension $\mathrm{T}$ over its whole life-time. Besides, the effect of different mean tensions cannot be combined.

\section{$\underline{\mathrm{N} \text { at a given } \mathrm{Rs}}$}

More simply, for a given target value of the $\mathrm{Rs}_{w c}$, being either a mean or a design value, the allowable $\mathrm{N}$ versus $\mathrm{T}$ can be calculated by equations (2) or (3). The corresponding T-N curves are shown in figure 14 below. It can be observed that, as for $\mathrm{T}-\mathrm{N}_{\mathrm{f}}$ (also plotted for comparison), these curves are straight lines in a log-log plot, but with a slope parameter equal to $b_{r}$, i.e. 1.5 . Besides, as the strength loss is a linear function of the number of cycles, the effect of different tensions can simply be combined by a Miner Sum, for a given target value of the Rswc. The actual Safety factor is then given by :

$$
\mathrm{SF}_{\mathrm{dyn}}=\mathrm{Rs_{Wc }} / \mathrm{T}_{\text {dynmax }}=R s_{\mathrm{wc}} / \max \left(\mathrm{DTF} * \mathrm{~T}_{\text {mean }}\right) \quad \text { (Equation 8) }
$$

taking the maximum of $T_{d y n}$ over all operations, that is still somewhat conservative, as it assumes that this maximum will happen at the end of rope lifetime. A more accurate assessment of SF versus time is also possible, that could be integrated in an in-service rope life management system.

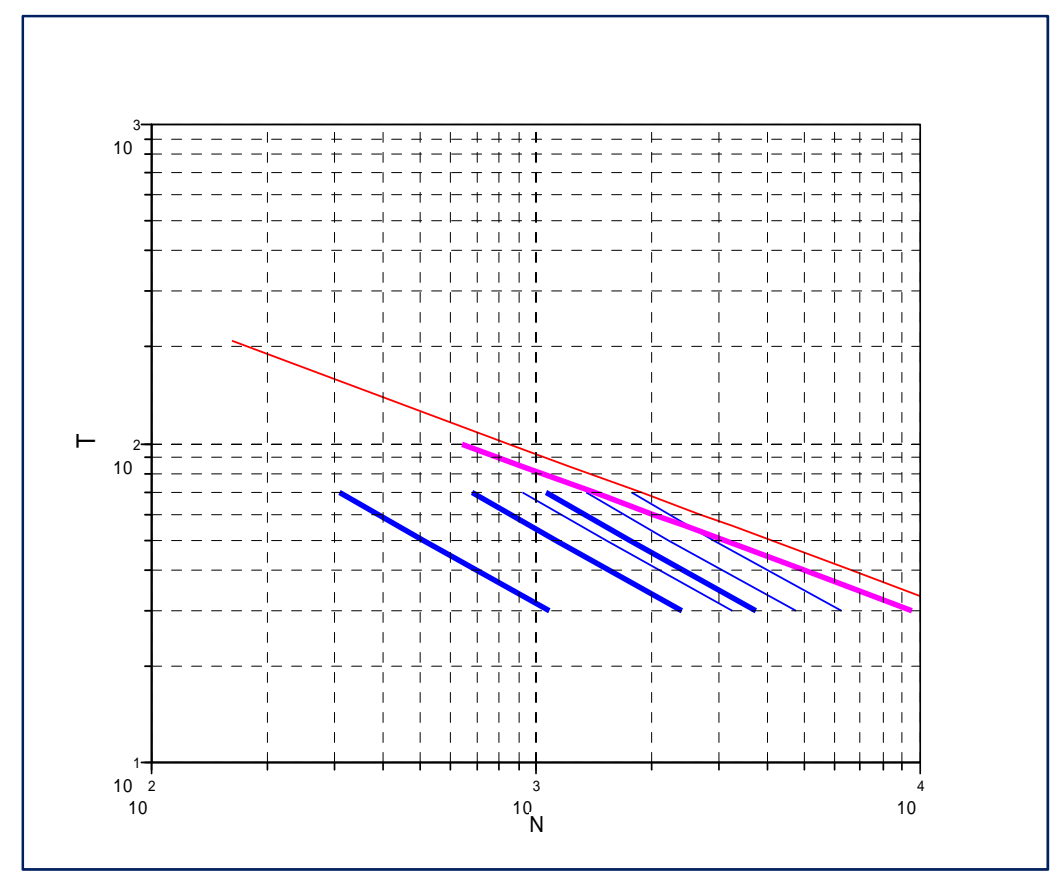


Figure 14. Tension versus allowable $N$ for 3 values $(120,135$, and150 kN)

of the mean (blue lines) and allowable (bold blue lines) Rswc;

$T-N_{f}:$ mean (red line) and design (bold pink line) also shown for reference.

\section{Conclusions}

A large set of tests has been performed on braided HMPE fibre ropes under CBOS loading. An analysis of cyclic bend over sheave test results was then performed in order to propose a model to predict the lifetime of deep water handling ropes: this was based on a linear expression for residual strength versus number of cycles $\mathrm{N}$, function of the applied (mean) tension, that can be used in order to predict either cycles to failure at a given tension or residual strength at a given fraction of lifetime.

Use of this model to predict two-load and variable load response gave satisfactory predictions.

While the data tend to justify the current approach of using quite high "Factors of Safety" in applications with intense CBOS, the Residual Strength model presented here provides the basis for a more rational approach: A direct assessment of the actual level of safety of the line, versus the applied (mean) tension(s) and the number(s) of CBOS cycles, based on a knowledge of system dynamic response.

In order to extend this approach to the large diameter fibre ropes required for deep sea installation of offshore equipment it is now necessary to develop the test database, to include large rope CBOS test results. Further work is also developing numerical modelling of braided rope behaviour on sheaves, in order to improve understanding of damage development.

\section{Acknowledgements}

This work was performed as part of a CITEPH (Concertation pour l'Innovation Technologique dans l'Exploration Production des Hydrocarbures) project. The authors are grateful to the other project partners, Technip, Subsea7, Imeca and Samson Ropes, both for their active participation in the project and for permission to publish this part of the work. The views expressed are those of the authors, and do not necessarily reflect those of their respective companies

\section{List of Symbols}

$a_{r}, b_{r} \quad$ Empirical parameters relating the rate of strength loss $Q$ to applied tension $T$

CBOS Cyclic Bend Over Sheave 


$\begin{array}{ll}\text { DTF } & \text { Dynamic tension Factor (ratio of maximum dynamic to mean static tension) } \\ \text { Frat } & \text { Normalized residual strength with respect to first cycle }=(\text { Rs- } T) /(R 1-T) \\ N_{f} & \text { Number of machine cycles to failure (= 2x CBOS cycles) } \\ \mathrm{Q} & \text { the rate of strength loss, } \mathrm{Q}=\mathrm{a}_{\mathrm{r}} \mathrm{T}^{\mathrm{br}} \\ \mathrm{Rd} & \text { Design value of residual strength, the mean Rs minus k standard deviations } \\ \mathrm{Rs} & \text { Residual strength } \\ \mathrm{Rs} & \text { Residual strength while cycling } \\ \mathrm{R}_{1} & \text { Residual strength after } 1 \text { cycle } \\ \mathrm{T} & \text { Applied Tension in Rope }\end{array}$

\section{References}

Bureau Veritas "Fatigue Strength of welded ship structures" NI 393 - (1994).

Davies P, Reaud Y, Dussud L, Woerther P, (2011) "Mechanical behaviour of HMPE and aramid fibre ropes for deep sea handling operations". Ocean Engineering 38, 2208-2214

Davies P, Lacotte N et al, (2013), Durability of Fibre ropes for deep sea handling operations, Proc OMAE 2013-11332, Nantes

DISH (Deep water Installation of Subsea Hardware) Joint Industry Project (2001-2006).

Durville D., (2010), Simulation of the mechanical behaviour of woven fabrics at the scale of fibers, International Journal of Material Forming, 3 :1241-1251,

Durville D., (2012) Contact-friction modeling within elastic beam assemblies: an application to knot tightening, Computational Mechanics, 49(6):687-707

Feyrer K, (2007) Wire ropes, Tension, Endurance, Reliability, Springer Berlin

Ghoreishi S.R., Cartraud P., Davies P. and Messager T., (2007) Analytical modeling of synthetic fiber ropes subjected to axial loads. Part I: A new continuum model for multilayered fibrous structures, International Journal of Solids and Structures, 44(9):2924-2942

Gilmore J, Stenvers D, Chou R, (2008) Some Recent Developments of Rope Technologies - Further Enhancements of High Performance Ropes, Proc. OCEANS08

Leech, C.M., Hearle, J.W.S., Overington, M.S., Banfield, S.J., (1993), Modelling tension and torque properties of fibre ropes and splices. In Proceeding of the Third International Offshore and Polar Engineering Conference Singapore 
Leech, C. (2002) The modelling of friction in polymer fibre ropes. International Journal of Mechanical Sciences, 621-642

Madsen H.O. , Krenk C. , Lind N.C. (1986) "Methods of Structural Safety”, Dover Press.

McKenna, H., Hearle, J., and O'Hear, N., (2004) Handbook of fibre rope technology, Woodhead Publishing limited

Nabijou S, Hobbs RE, (1995) "Frictional performance of wire and fibre ropes bent over sheaves", Journal of strain analysis for engineering design, vol. 30, 1, pp. 45-57

Pickett, A. K., Sirtautas, J., Erber, A., (2009), Braiding Simulation and Prediction of Mechanical Properties, Applied Composite Materials, 16 (6), pp. 345-364

Thomas R, Gilmore J, "Deepwater synthetic lowering and lifting lines with enhanced cyclic bend fatigue resistance", (2009), Proc. DOT, New Orleans

Torben S, Ingeberg P, Bunes O, Bull S, Paterson J, Davidson D, (2007) "Fibre rope deployment system, for ultra deepwater installations", OTC18932

Tornqvist R, Strande M, O'Cannell D, Gledhill P, Smeets P, Gilmore J, (2011) “Deployment of Subsea equipment: qualification of large diameter fiber rope for deepwater construction applications", OTC21588

Vennemann O, Tornqvist R, Ernst B, Winter S, Frazer I, (2008), "Bending fatigue tests using a suitable NDT method to determine lifetime of large diameter wire ropes for offshore lifting applications", Proc. OMAE Portugal, paper 57128.

Wu, H-C, Seo, MH, Backer, S., and Mandel, JF, (1995), Structural modeling of double braided synthetic fiber ropes. Textile Research Journal November, 619-631, 